\title{
Urban energy performance calculation based on EPBD standards GIS4ENER tool
}

\author{
Gema HERNÁNDEZ-MORAL, Fundación CARTIF, Spain \\ Víctor Iván SERNA-GONZÁLEZ, Fundación CARTIF, Spain \\ Francisco Javier MIGUEL-HERRERO, Fundación CARTIF, Spain \\ César VALMASEDA-TRANQUE, Fundación CARTIF, Spain
}

\begin{abstract}
Climate change will have a strong impact on urban settings, which will also represent one of the major challenges (world's urban population is expected to double by 2050, EU buildings consume $40 \%$ final energy and generate $36 \% \mathrm{CO}_{2}$ emissions). A plethora of initiatives address this challenge by stressing the underlying necessity of thinking globally but acting locally. This entails the inclusion of a varied set of decision-makers acting at different scales and needing robust, comprehensive and comparable information that can support them in their energy planning process.

To this end, this paper presents the GIS4ENER tool to support energy planners at different scales by proposing a bottom-up approach towards the calculation of energy demand and consumption at local scale that can be aggregated to support other decision-making scales. It is based on three main pillars: the exploitation of publicly available data (such as Open Street Maps, Building Stock Observatory or TABULA), the implementation of standardised methods to calculate energy (in particular the ISO52000 family) and the use of Geographic Information Systems to represent and facilitate the understanding of results, and their aggregation.

The paper presents the context, main differences with other approaches and results of the tool in Osimo (IT).
\end{abstract}

\section{Keywords}

Energy planning, Multi-scale, Public data sources, ISO standards, Geographic Information Systems, Sustainable Development

\section{Introduction}

Climate change can be considered one of the most relevant current threats to human development. In particular, urban areas represent both the biggest challenge among all sectors and scales, and also hold the biggest potential for change. Especially when considering that the built environment consumes $40 \%$ of final energy and generates $36 \% \mathrm{CO}_{2}$ emissions in Europe. Moreover, according to the Quito declaration on sustainable cities and human settlements for all [1], the world's urban population is expected to double by 2050, making urbanization process one of the twenty-first century's most transformative trends. Urban areas need to play a relevant role in the fight against climate change, since they will have a major impact on the future of sustainable development. 
In order to address these relevant challenges and promote sustainable development considering its three main pillars (social, economic, environmental), a plethora of initiatives and agreements have emerged, both at international and continental level (e.g. Millenium Development Goals [2], Sustainable Development Goals [3], Paris Agreement [4], New Urban Agenda [5], etc.). When focusing on the energy sector, the principles shared are common: to ensure environmental sustainability by promoting clean energy and sustainable use of land and resources in urban development; as well as the underlying thought for the need to think globally and act locally. These two concepts are translated into directives and norms which exert obligations at different levels (national, regional and local).

Necessarily, these different levels imply the appearance of different actors with different levels of decision making. However, some general patterns are observed in the generation of action plans (be it National Energy Action Plans, Regional Energy Strategies, local action plans, etc.), as it can be seen in the figure below: general objectives are broken into strategic objectives, which are more specific. These should be supported by indicators, which can be qualitative or quantitative, and which can serve both to analyse the baseline situation, as well as monitor the progress of a strategy. In order to calculate these indicators, variables are needed, which are extracted from the analysis of data.

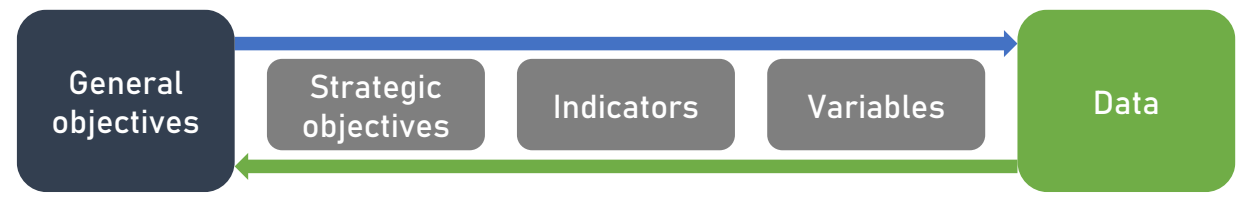

Figure 1. Generic steps of the structure of action plans at different scales. Source: own elaboration

As it can be observed, data can be considered to represent the most important basis for a robust decision-making process, and needs to be deployed in order to evaluate and monitor the objectives established at any level of this process. In this respect, nowadays there is a vast emergence of data at different scales, which is increasingly becoming publicly available and can support these processes. The appeareance of big data analytics, artificial intelligence and other means of data exploitation represents a massive opportunity for supporting action plans. In this context, the harmonisation of approaches by following relevant calculation standards, as well as the deployment of common data models to represent the information is crucial in order to ensure the most efficient exploitation of these data. However, the most critical question needs to be clarified: what is the problem that we need to solve with these data?

In this context, the objective of this paper is to present the GIS4ENER tool, which is capable of exploiting publicly available data that can support energy planning decision-makers both at urban and regional level, by mapping energy demand and consumption and by presenting the results with different levels of detail. Additionally, these results can be integrated into national-scale tools (such as Energy Plan [6]) to enhance the accuracy of its calculations and embrace the local conditions of the analysed area.

This multi-scalar approach is presented in the paper by firstly approaching the energy planning context in Europe and by analysing the tool need (section 2). Then, the functionalities of the GIS4ENER tool are explained (section 3), as well as how the tool can be integrated within planning processes (section 4). Finally, some conclusions and future work are suggested (section 0) and acknowledgements presented (section 6).

\section{Energy planning context in Europe and tool need}

This section focuses on the specific context in Europe with respect to energy planning: agreements, initiatives and directives at this level will be explored, energy competences in the EU and the necessity to focus on the local areas. Finally, the tool need is explained, as well as which main data is available to support energy planning tools. 


\subsection{Agreements, initiatives and directives at the EU level}

The most relevant directives for the purpose of this paper in the European context are the Energy Performance of Buildings Directive (2018/844/EU) [7], the Renewable Energy Directive (2009/28/EC) [8] and the Energy Efficiency Directive (2012/27/EU) [9]. These emerge from the "Clean Energy for All Europeans" [10] package, and the necessity to move towards a low carbon economy, setting a series of objectives. Nonetheless, these challenges have been reinforced with the appearance of the European Green Deal [11], including 50 specific actions to fight against climate change and turn Europe into the first climate neutral continent by 2050. Among these initiatives, the Renovation wave [12] is the most directly related to the purpose of this paper, since it aims to double annual renovation rates in the next ten years, with the objective to "enhance the quality of life for people living in and using the buildings, reduce Europe's greenhouse gas emissions, and create up to 160,000 additional green jobs in the construction sector", thus directly tackling the built environment in urban areas.

\subsection{Energy competences in the EU}

In order to plan the roll-out of these Renovation Wave objectives, it is necessary to understand the framework in terms of energy competences in the EU, since this implies the necessity of different decision-making levels. According to analyses performed on Committee of the Regions [13] data, of the EU28, there are 8 countries with legislative powers at the sub national level, whereas the rest of the countries do not count on this privilege. However, from the latter, there are 14 in which the regional level holds energy competences ( +8 with legislative powers). Finally, all of the countries have energy competences at the local level to be deployed through the municipalities.

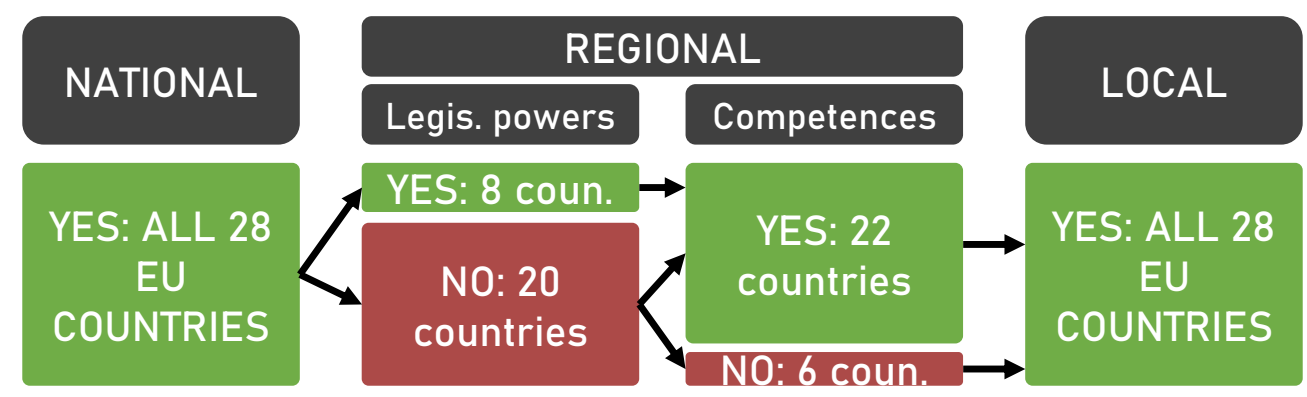

Figure 2. Energy competences in the EU. Source: own elaboration

This varied panorama in Europe suggests the adequacy of proposing methods that can be homogeneously used by decision-makers and whose results can be easily aggregated and disaggregated at different scales.

\subsection{Local-area focus}

Nonetheless, it is crucial to acknowledge the local characteristics of urban areas. In this context, the reference document in Europe, which is the transposition of the New Urban Agenda, is the Pact of Amsterdam (Urban Agenda for the EU) [5]. Aiming for three main pillars: better regulation, better funding and better knowledge, it establishes 12 priority themes where to tackle transformative commitments in the social, economic and environmental fields.

Particularly relevant to this paper is the pillar of better knowledge, since the proposed tool directly aims at supporting the decision-making process by enforcing the knowledge base in energy planning processes, impacting mainly the "Housing" and the "Digital Transition" priority themes. This will contribute principally to the environmental transformative commitment, and have an indirect impact on the economic and social fields as well. 


\subsection{Energy Planning tool need}

Following the actions ensuing form the Urban Agenda for the EU [5], two are crucial to justify energy planning tools' need. Firstly, there is a need to support impact assessments by easing the implementation of EU legislation at urban level. In particular, the need to directly consider in the local level the impact of EU legislation is requested by deploying better methods and specific tools. Secondly, the boost of knowledge is highlighted, both in terms of experiences as well as monitoring results. Reliable data is required and should be exchanged, always considering relevant EU data protection legislation and with the aim to minimise administrative burdens.

\subsection{Data and standards to support energy planning tools}

Finally, given all the challenges, requirements and objectives, it is necessary to identify the currently available data that can support these energy planning tools, which can be classified into three groups:

- Building stock data: the characteristics of the built environment (envelope, typical values, energy systems etc) are crucial for determining the energy demand and consumption of a given area. In this respect, projects like the Building Stock Observatory (BSO) [14] or EPISCOPE/TABULA [15] offer a series of values.

- Geometric data: not only the building typologies, but also the geometric characteristics (surface area, number of floors, etc) of the buildings are essential to estimate the energy demand. In this line, cadastral data could be considered the most reliable source, especially when it follows standards like the INSPIRE Directive in the EU [16]. However, in order to cover a broader area (not only EU) resorting to community initiatives such as Open Street Maps (OSM) [17] is advisable.

- Calculation standards: related to energy calculations, the most relevant standard is the family of ISO 52000 [18] standards, as reflected in the Energy Performance of Buildings Directive [7]. In particular, ISO 52000-1, ISO 52003-1, ISO 52010-1, ISO 52016-1 and ISO 52018-1.

\section{GIS4ENER tool}

The GIS4ENER tool addresses all the challenges posed in the previous section, since its main objective is to provide an energy decision support tool to map energy demand at urban and regional level calculated following EPBD calculation methods and using public data. The three main pillars in the development of the tool are:

1. Public data use: all of the data used by the tool are publicly available. The main data source is OSM, which provides information on the geometry of buildings and for categorizing the building into typologies, whereas other data used is related to building constructive elements, taken from TABULA and Building Stock Observatory.

2. Calculation method based on EPBD standards: to provide comparable results, a calculation method based on the ISO 52000 standards [18] for energy calculation referred to in the EPB Directive has been implemented, which are the same standards followed in the Energy Performance Certification tools.

3. Exploitation of Geographic Information Systems (GIS): GIS4ENER will display information not only at Municipal level, but also information mapped using GIS technologies in different types of format for covering different functionalities. 


\subsection{Main differences with other tools}

Currently there are projects sharing a similar approach to that of GIS4ENER. Some of these projects can be seen below, in which the main differences with the GIS4ENER platform are indicated:

- Pan-European Thermal Atlas [19] has been developed as part of the work in Heat Road Map Europe project. In this Atlas the energy demand for Europe has been estimated based in different parameters. The model is a geographic representation of heating and cooling demands (among other parameter) for 14 European countries. The main difference with the present tools is that in their developments only a typology of residential building is use for each country and the morphology of the buildings is not used.

- Hotmaps [20] has as aims the development of a heating and cooling mapping and planning toolbox and to provide this information for EU28. In this tool for having more accurate outputs it is necessary to collect information about the typologies of the building, as opposed to what happens in the tool presented here, where the information of the typologies has been gathered in advance at European level.

- Thermos (OSM) [21] is an online tool dedicated to offer a scenario for district heating design, considering the geometrical features given by OpenStreetMaps. In this case, the solution does not consider building typologies or goes up to city level, consequently it is a useful tool for making decisions only up to district level.

- City Energy Analyst (CEA) [22] is a toolbox for ArcGIS. It includes a complete set of interconnected applications that can be fed with data at district level. The CEA displays automatically heating maps, makes energy simulations and comparisons between sceneries, and offers reports for optimization of energy. This tool is more oriented towards engineering analysis in order to help on singular projects, but does not go further into policies making and decisions at higher level.

- Planheat tool [23] is a plug-in for QGIS designed inside the Planheat project. It has three modules (mapping, planning and simulation) and a Key Performance Indicator panel. This tool is useful for mapping heating and cooling needs at city or district level, even offering layouts for pipe deployment for district heating. This project shares the OSM public data as one base for energy calculations, meanwhile GIS4ENER takes advantage of typology building features from Tabula and BSO, going one step further towards a more accurate calculation of energy demand, not only based on the geometry of the buildings. Moreover, GIS4ENER is independent from QGIS.

- SimStadt [24]: is a tool for the simulation of urban environments which uses CityGML [25] models as input, and INSEL [26] as calculation engine, developed by the Hochschule für Technik Stuttgart. Whereas this tool is highly useful to calculate energy demand, detailed inputs in CityGML format are required, as well as the definition of a Buildings Physics Library. These inputs are directly provided in the GISAENER tool.

\subsection{Phases of the tool}

This section includes everything necessary to be able to generate a spatial mapping of the annual heating and cooling demand in buildings, taking as references open code and open data resources, and trying to develop a procedure that can be used in all Member States with minor modifications.

The process is divided into three phases, as per the following figure. Firstly, data input should be established. This is composed mainly of three elements: (1) Climatic data (determines the climatic 
conditions in which the building is located, strongly impacting the results), (2) geometry and (3) building characterisation (typology data). Secondly, robust calculations for the calculation of heating and cooling energy demand based on standards are established. Finally, the data output should be treated in order to serve the needs for which it has been devised. In this case, the objective is to have a heat density map, as well as hourly energy demand and consumption values for the whole municipality.

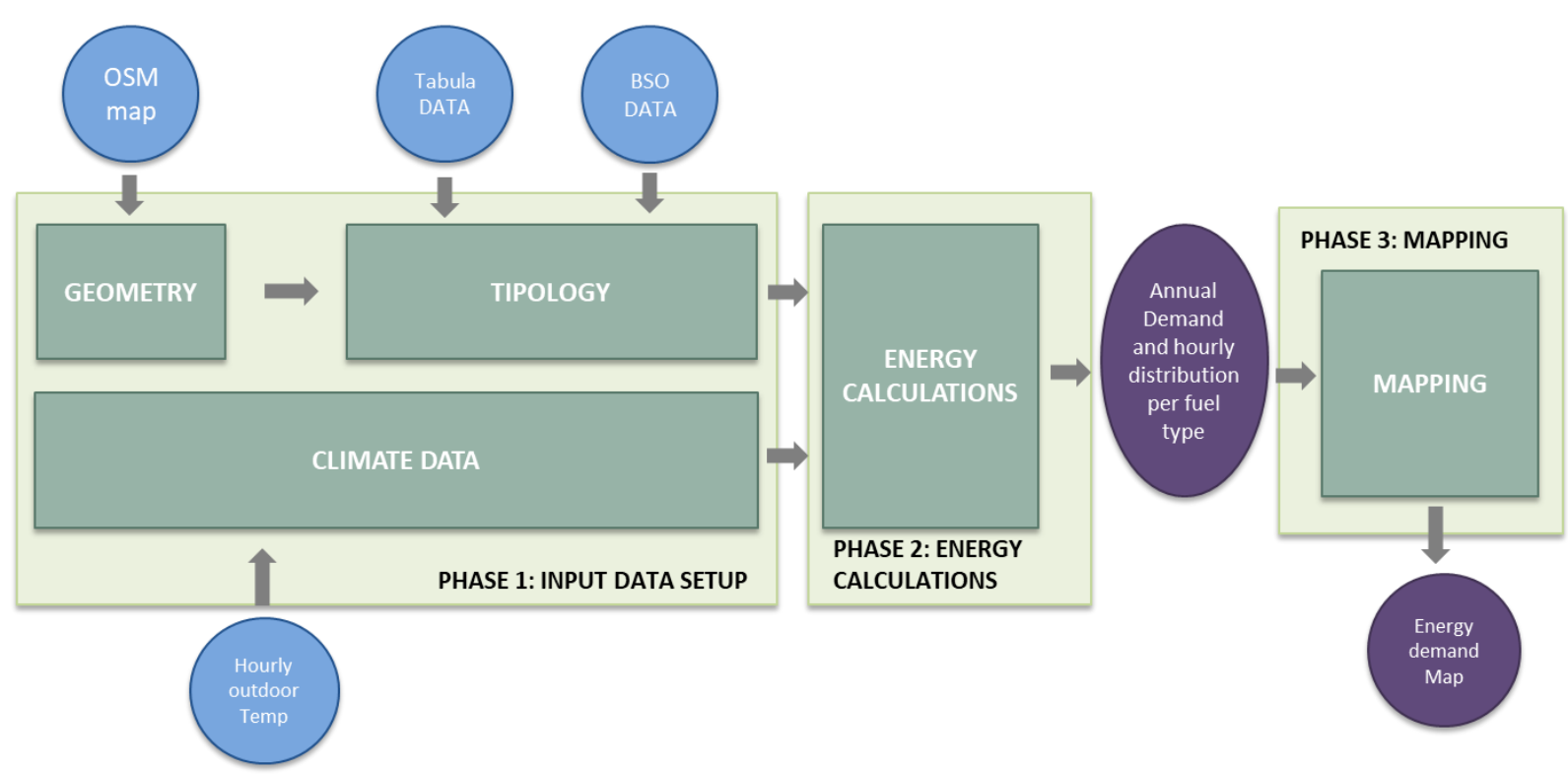

Figure 3. Tool scheme: phases, imputs and outputs. Source: own elaboration

The phases are widely explained in the following subsections.

\section{Phase 1: Input Data setup}

\section{Geometrical data of the building}

The geometrical data necessary for the calculations include the buildings geometry and constructive features, and their geographical position.

The tool requires of the processing of a map with geometrical information of the buildings and also with information about the uses of the building. For that the maps that are offered by Open Street Map are used. Before the execution of the tool, it is needed to download the map corresponding to the municipality of interest from the OSM website. The output format is normalized, and consequently the pre-processing of data required is minimal. This geometry processing module extracts the geometric information from the OSM translating the geographical information. The gross floor area, the surface of the façade, roofs and floors of the building are calculated in order to be used in the subsequent calculations.

\section{Typology data}

The typology data are a special part of the physical features from the buildings, and deserve a separated treatment, considering the specific dedication for the usage of proper selection criteria that let the procedure cluster the buildings into groups of similar features (the typologies themselves).

Considering the Tabula/Episcope and the BSO, the information from these sources is not available in a digital normalized format that could be read automatically from a software program. This has been detected as a major hurdle in terms of using these data for the goal that precisely they were created, and 
explains why there have not been intensively used in automated processes like ours, instead as single-use consultations online.

To create a link between these OSM data and the typology data it has been necessary to create a procedure to indicate it a given building is considered residential, non-residential or should be discarded. The "discard" group include the buildings that are not conditioned and not have energy demand. The energy calculation will ignore these buildings in the next phase. Besides, if there is enough information the residential group is divided into other groups with more information for the cataloguing in the different typologies. The groups are: Apartment buildings, Single Family Houses, Multi Family Houses and Terrace Houses.

It is important to note that this information is not always present so for some buildings we do not know the exact category, so some "by default" cases are needed in order to solve that. This is considered as a major hurdle and ties directly to the versatility of the tool towards its usage in non-European cases.

The result of this process is a code for each building that is compatible to the codification used in our building typology sources, the Tabula/Episcope site, and the Building Stock Observatory, both containing data that relate energy consumptions with the typology of the building.

\section{Climate data}

The climate data are the third pillar of the set of data, and in the first versions of the software include hourly temperature values for the location being considered during a whole sample year.

The first step is obtaining the data from one complete year for the evaluated location. Unfortunately, the availability of reliable free weather data sources has even decreased during the last years, making the work of automatizing the data gathering process not possible.

For the goal of obtaining valid values for the project, the data have been taken from MERRA-2 initiative from SoDa (Solar radiation Data) website [27]. Downloading the data of a specific geographical location and with a simple post-processing the data needed is ready.

The application also has tailored values of comfort temperatures, as they are shown in Eurostat statistics [28] that contain these ranges of temperature values. It has been added a small threshold of three degrees ${ }^{\circ} \mathrm{C}$ in order to simulate a realistic behaviour of the users towards their temperature comfort limits.

Along with the comfort values of the location considered, the Heating Degree Days (HDD) and Cooling Degree Days (CDD) values are calculated for the whole year because these values will be directly used for the energy needs calculations, as it will be explained in the next paragraphs.

\section{Phase 2: Energy calculations}

The objective of the tool is the calculation of the following parameters for each building: (1) heating demand, (2) cooling demand, (3) hot water, (4) heating and hot water consumption per vector. An additional objective is (5) the calculation of the hourly hot water, cooling and heating demand for the municipality in one year (i.e., 8760 values for each parameter). Thus, it must be noted that the first set of calculations are performed for each building, and those at the municipality level are done by adding the results of all buildings.

\section{(1) Heating demand}

For calculating the heating demand, the following formula is used:

$$
Q_{\text {heating }}=P_{\text {specific }} * H D D / 1000 \text {, }
$$

where HDD is the Heating Degree Days for the entire interval and $P_{\text {specific }}=U *$ Surface of the building. 
In our case this $\mathrm{P}_{\text {specific }}$ is calculated for each type of surface, specifically:

$$
P_{\text {specific }}=\text { Uvalue }_{\text {walls }} * A_{\text {rea }} \text { walls }+ \text { Uvalue }_{\text {roof }} * A_{\text {rea }}+\text { Uvalue }_{\text {windows }} * A_{\text {rea }} \text { windows }
$$

\section{(2) Cooling demand}

For calculating the cooling demand, the following formula is used:

$$
\mathrm{Q}_{\text {cooling }}=\mathrm{P}_{\text {specific }} * \mathrm{CDD} / 1000 \text {, }
$$

where CDD is the Cooling Degree Days for the entire interval and $\mathrm{P}_{\text {specific }}$ is the same that those calculated for the heating demand

\section{(3) Hot water}

For the hot water demand values, parameters about the hot demand per $\mathrm{m}^{2}$ are used following the simple formula:

$$
Q_{\text {hotwater }}=Q_{\text {hotwater } / \mathrm{m}^{2}} * \text { Gross Floor Area }
$$

This $Q_{\text {hotwater } / \mathrm{m}^{2}}$ is taken differently if the building is residential or not-residential. For the non-residential buildings information from Building Stock Observatory is used, and it is different for each country and for each interval of year of construction. In the case of the residential building, TABULA data are used and the parameters are different for each country but also for each type of typology defined (for type of building and for each interval of year of construction).

\section{(4) Heating and hot water energy consumption per vector}

In the case of the heating energy consumption per vector the approach is also slightly different for residential or non-residential buildings.

The different vectors that are considered are those provided by TABULA (that is the most complete source data used by the tool) are the following: Gas, Oil, Coal, Biomass, Electricity and District Heating.

In the case of the residential buildings, the energy systems considered in the corresponding typology of the building (up to three systems per typology) are considered with their efficiencies. Also, distribution and storage losses are considered. Besides auxiliary energy to uses these systems (usually electricity) is calculated. All this information is extracted from TABULA and the calculation are carried out following the methodology proposed by TABULA.

For the case of the non-residential building a simpler methodology is used. In this case the values of the energy consumption per vector and per $\mathrm{m}^{2}$ are used (but differently per country). The values are extracted from BSO and there is only information for four vectors: Gas, Oil, Coal and Electricity. In the noresidential case, it is considered that each building has the four vectors in the proportion indicated by the BSO data.

In the case of the hot water energy consumption the procedure is the same as the heating consumption's: TABULA for residential buildings and BSO for those non-residential one, with the same methodology explained before.

\section{(5) Hourly hot water, cooling and heating demand for the municipality}

In this case the objective is to calculate the hourly demand for the hot water, cooling and heating demand for the complete municipality. The way to do that is the same for the cooling and heating demand but different for the hot water demand

For heating and cooling calculation, demands of all the buildings are summed and after that, this is distributed using the hourly HDD and CDD. In this way we have the following formulas: 


$$
\begin{aligned}
& \text { Heating demand } \text { hour } \mathrm{i}_{\text {= Energy demand total }} \text { HDD }_{\text {hour } \mathrm{i}} / \mathrm{HDD} \\
& \text { Cooling demand } \text { hour } \mathrm{i}=\text { Energy demand total }^{*} \mathrm{CDD}_{\text {hour } \mathrm{i}} / \mathrm{CDD}
\end{aligned}
$$

In the case of the hot water demand calculation, it has been assumed that the demand of hot water is constant along the year but excluding the night periods. Specifically, it has been distributed between the 6:00 to 24:00 for every day.

Then, the result is three data arrays (one for cooling, one for heating and one for hot water demand) of 8760 values each.

\section{Phase 3: Data output and mapping}

The calculations are performed at building level and the results are used to enrich the original dataset that comes from the OSM, so the results are mapped in a GeoJSON format (extensively used for GIS data, especially for data to be used in web applications).

In the mapping phase the objective is to use this dataset to create a $100 \mathrm{~m} \times 100 \mathrm{~m}$ grid with the heating and hot water demand corresponding to each square stored in a GIS file. The steps are the following: using GIS procedures split the OSM map into $100 \mathrm{~m} \times 100 \mathrm{~m}$ squares; associating each building through its centroid to each square; sum up each building heating and hot water demand value with the others belonging to the same square location; creating a raster file (tiff) with this information. This raster file can be visualized and used for feeding other tools.

\subsection{Results}

In this section the results of the tool for one municipality are presented, in particular, for Osimo (Italy). For the execution of the tool, some data has been downloaded in advance: the map for Osimo from OSM and climate data from MERRA-2.

As result, two different set of outputs are obtained: data in form of tables and data in form of maps.

The tabulated data contains: energy demand for the entire municipality (see Table 1), divided into heating, cooling and hot water demands; the percentage of energy consumed per energy vector (see Table 2); and, finally, the hourly data for the HDD, CDD, heating, cooling and hot water demand for an entire year (see Table 3).

Table 1: Energy demand for the entire Osimo municipality

\begin{tabular}{|l|l|}
\hline Energy demand & GWh/year \\
\hline $\begin{array}{l}\text { Total heating } \\
\text { demand }\end{array}$ & 150,13 \\
\hline $\begin{array}{l}\text { Hot water } \\
\text { demand }\end{array}$ & 33,73 \\
\hline $\begin{array}{l}\text { Total cooling } \\
\text { demand }\end{array}$ & 5,49 \\
\hline
\end{tabular}

Table 2. Distribution of the energy consumption per vector for Osimo municipality

\begin{tabular}{|l|l|}
\hline Energy vector & $\%$ \\
\hline Gas & 93,48 \\
\hline Oil & 3,82 \\
\hline Biomass & 0 \\
\hline Electricity & 0,92 \\
\hline Distrct Heating & 0 \\
\hline Coal & 0,80 \\
\hline
\end{tabular}

Table 3. Hourly energy demand, CDD and HDD for Osimo municipality (extract for 12 hours)

\begin{tabular}{|c|c|c|c|c|c|c|}
\hline Date & $\begin{array}{c}\text { UT } \\
\text { time }\end{array}$ & HDD & CDD & $\begin{array}{c}\text { Heating } \\
\text { demand }\end{array}$ & $\begin{array}{c}\text { Cooling } \\
\text { demand }\end{array}$ & $\begin{array}{c}\text { HW } \\
\text { demand }\end{array}$ \\
\hline
\end{tabular}


Hernández-Moral, G; Serna-González, V.I.; Miguel-Herrero, F.J; Valmaseda-Tranque, C.
Urban energy performance calculation based on EPBD standards: GIS4ENER tool

\begin{tabular}{|c|c|c|c|c|c|c|}
\hline & & & & $\begin{array}{c}\text { hourly } \\
\left(\mathrm{kWh} / \mathrm{m}^{2}\right)\end{array}$ & $\begin{array}{c}\text { hourly } \\
\left(\mathrm{kWh} / \mathrm{m}^{2}\right)\end{array}$ & $\begin{array}{c}\text { total } \\
\left(\mathrm{kWh} / \mathrm{m}^{2}\right)\end{array}$ \\
\hline $01 / 01 / 2019$ & $1: 00$ & 12,42 & 0,00 & 47833,87 & 0,00 & 0,00 \\
\hline $01 / 01 / 2019$ & 2:00 & 12,69 & 0,00 & 48873,74 & 0,00 & 0,00 \\
\hline $01 / 01 / 2019$ & $3: 00$ & 12,85 & 0,00 & 49489,96 & 0,00 & 0,00 \\
\hline $01 / 01 / 2019$ & 4:00 & 13,02 & 0,00 & 50144,69 & 0,00 & 0,00 \\
\hline $01 / 01 / 2019$ & $5: 00$ & 13,09 & 0,00 & 50414,28 & 0,00 & 0,00 \\
\hline $01 / 01 / 2019$ & 6:00 & 13,15 & 0,00 & 50645,36 & 0,00 & 5134,59 \\
\hline 01/01/2019 & 7:00 & 13,22 & 0,00 & 50914,96 & 0,00 & 5134,59 \\
\hline $01 / 01 / 2019$ & $8: 00$ & 12,06 & 0,00 & 46447,38 & 0,00 & 5134,59 \\
\hline $01 / 01 / 2019$ & 9:00 & 10,25 & 0,00 & 39476,42 & 0,00 & 5134,59 \\
\hline $01 / 01 / 2019$ & $10: 00$ & 9,48 & 0,00 & 36510,88 & 0,00 & 5134,59 \\
\hline $01 / 01 / 2019$ & 11:00 & 8,98 & 0,00 & 34585,20 & 0,00 & 5134,59 \\
\hline $01 / 01 / 2019$ & $12: 00$ & 8,63 & 0,00 & 33237,22 & 0,00 & 5134,59 \\
\hline$\ldots$ & $\ldots$ & $\ldots$ & $\ldots$ & $\ldots$ & $\ldots$ &. \\
\hline
\end{tabular}

The hourly data for the cooling and the heating for a year has been represented in a chart that can be seen in the following picture:

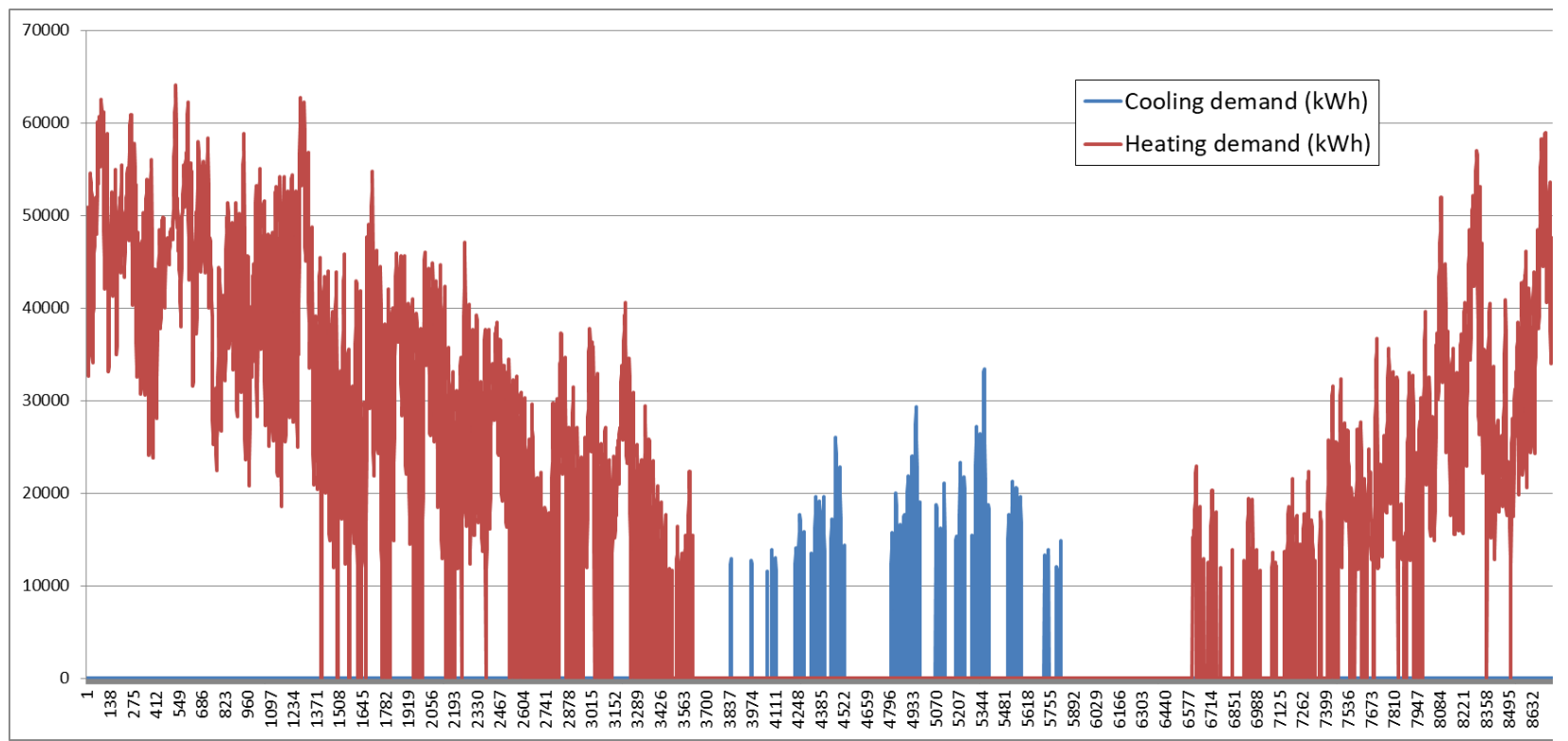

Figure 4. Hourly heating and cooling demand in Osimo municipality. Source: own elaboration

Regardind the data in form of maps, firstly there is a GeoJSON file containing the sum of the heating demand and hot water demand for each building (see Figure 5) and, secondly, a raster file (in tiff format) with the sum of the heating demand and hot water demand but in this case for each $100 \mathrm{~m} \times 100 \mathrm{~m}$ tile (see Figure 6). 


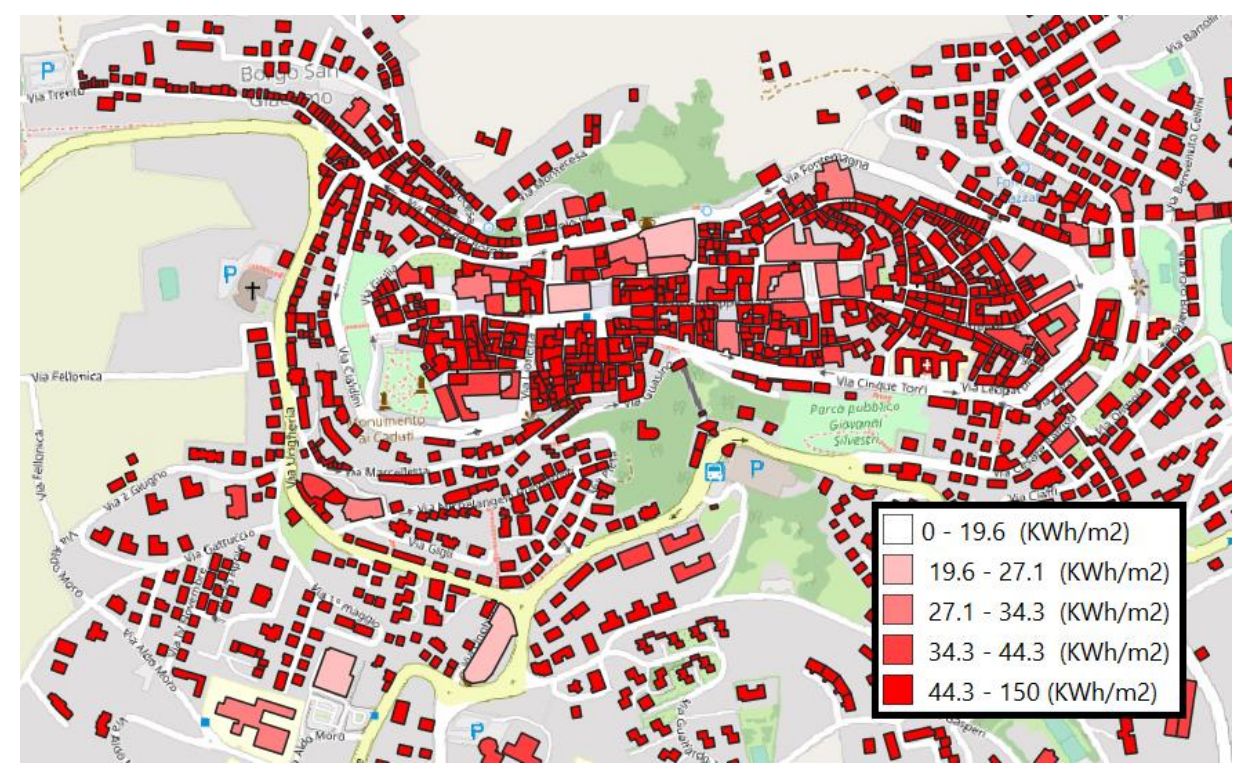

Figure 5. Heating and Hot water demand per building in Osimo municipality. Source: own elaboration

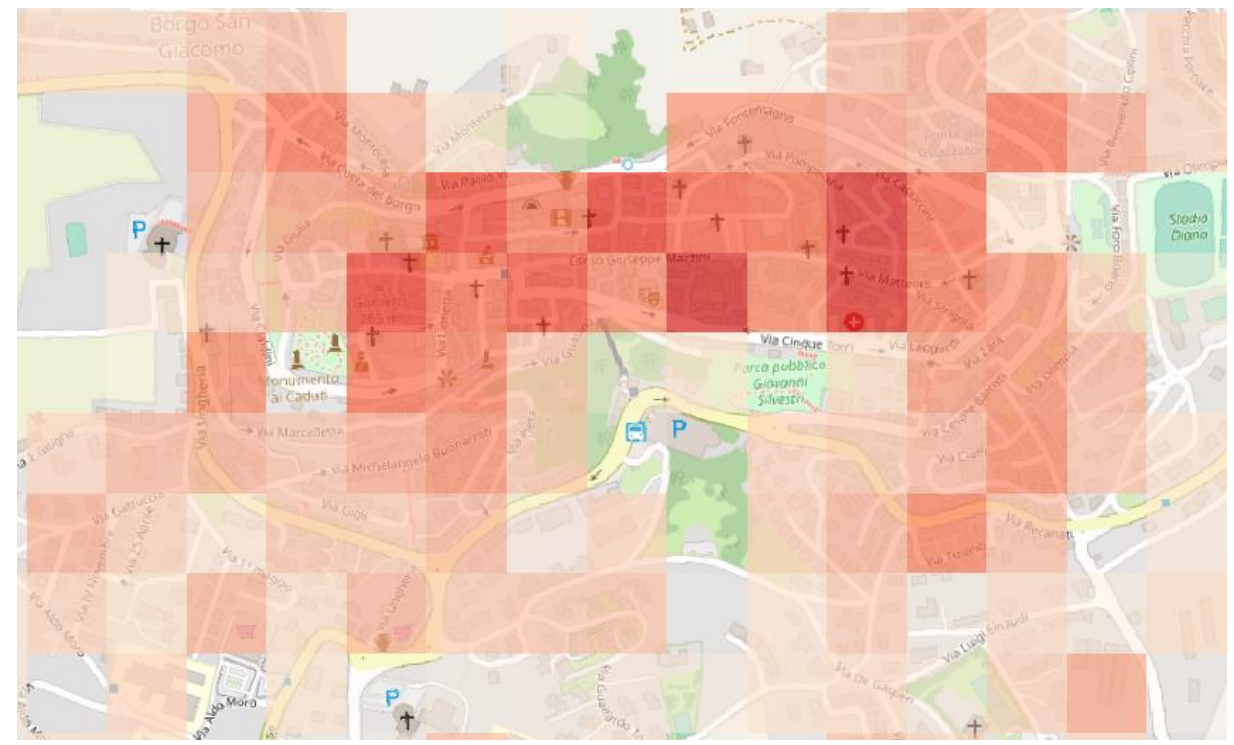

Figure 6. Heating and Hot water demand in Osimo municipality in 100mx100m grid. Source: own elaboration

\section{Integration of the tool within planning processes}

The introduction has presented a general process followed in the generation of action plans. As it has been explained, this tool exploits data (sources as OSM, Building Stock Observatory, or TABULA), to extract the necessary variables (building heights, year of construction, $U$ values, etc) to calculate the desired indicators (e.g. energy demand, and energy consumption per energy vector). 


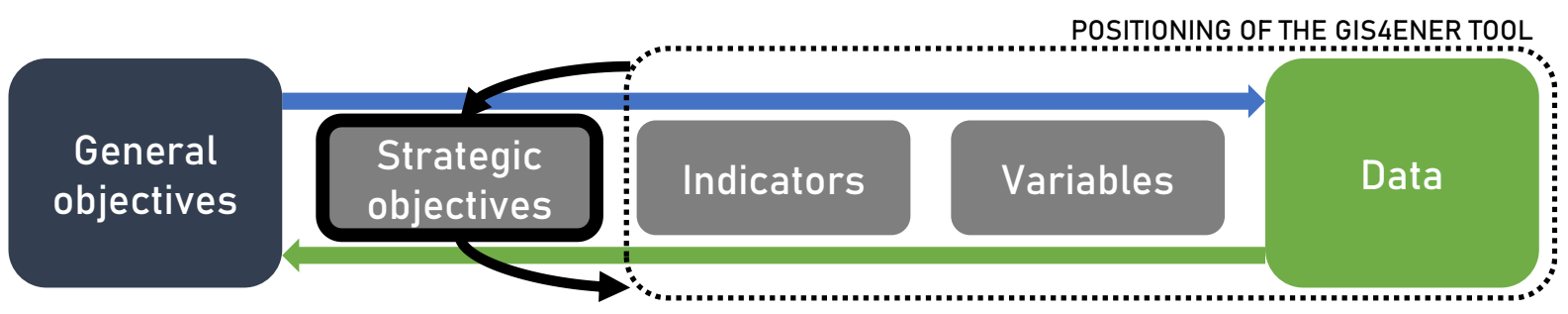

Figure 7. Positioning of the GIS4ENER tool. Source: own elaboration

This approach can serve as a basis to construct technical scenarios for a strategic heat supply by enabling to quantify heating, cooling and domestic hot water demand and consumption, and enables to match it in a future process it to the available heat sources in the area, heat savings potentials based on the implementation of energy conservation measures or the implementation of renewables, thus highly aligned with the objectives expressed in the European Commission's initiative, Renovation Wave. This process should be performed in an iterative manner, in order to be able to develop technical alternatives and scenarios that end up matching the general objectives established. Finally, in order to complete the cycle of the energy planning process, it would be necessary to evaluate existing framework conditions and identify key stakeholders, as well as propose an implementation plan based on the detected strategic and general objectives.

Moreover, in terms of scope, this tool can be applied preferably within any country in Europe, since there are applicable data sources to characterise the building stock in this geographical scope (e.g. Building Stock Observatory and TABULA). Otherwise, the user would need to generate a catalogue to characterise their building stock by following an excel sheet. Despite this fact, it is worth noting that technically, the tool could be applicable in any given country worldwide, since it has been designed towards its replication by choosing data sources that are available worldwide: weather services from MERRA-2 can be applied to anywhere in the globe, and Open Street Maps, which could exist in any place in the world driven by community initiative.

\section{Conclusions and future work}

Given the needs and challenges of the energy planning sector, tools like GIS4ENER represent an important progress, due to its capacity to exploit publicly available data to support multi-scale decisionmaking. This way, different stakeholders can be addressed who share the same knowledge through the analysis of clear and understandable results which are presented through the deployment of GIS and maps, inherent to any planning related to urban areas. Moreover, the comparability of the results is ensured by relying on the application of well-known standards. This, together with the approach to exploit world-wide available data, makes the replicability of the method worldwide possible, even when the coverage can be ensured for the moment for European countries.

In terms of next steps, three main aspects can be highlighted. Firstly, to be able to enhance the planning of strategic objectives, it would be advisable to integrate this method with the application of energy conservation measures or action, and specifically with the optimization processes that enable to generate scenarios and automatically simulate and derive the best combination of these actions to be applied by evaluating their impact. Secondly, these scenarios generated and the baseline scenario need to be compared with the energy supply available, as well as with the renewable energy potential, to be able to boost the implementation of renewables and further advance towards a low carbon economy. Finally, an increase in data accuracy would be required to be able to provide more robust results. In particular: 
- Detection of neighbouring buildings, since grouped buildings help to reduce the energy demand by substantially reducing heat losses from neighbouring walls in comparison to external ones.

- Identification of zones in urban settings, to identify where the types of buildings are clearly different from the rest of the building set considered, as an alternative to having relevant building characterisation data such as the year of construction or the height.

- Real occupation for the buildings, since not all of them are occupied and should not increase the resulting energy consumption. For the moment, this fact is considered by using a factor created through information gathered via Eurostat.

- User behaviour: similar to the previous bullet, the consideration of the daily usage of the buildings by simulating the standard behaviour of the users can have an impact on the energy consumption of a building and also enable to identify situations of energy poverty.

All in all, key challenges remaining are mostly related to increasing the accuracy of data: better characterising the building stock, having a more realistic approach towards the energy consumption by including real consumption patterns which consider the occupation as well as the behaviour of users, etc. It is clear that with the current advances in technologies (smart sensors, IOT devices, etc) and the application of big data analytics or artificial intelligence will pave the way for more robust decisionmaking and the application of location intelligence. However, knowing the answer to the question "what do we need these data for?" remains at the core, together with the main beneficiaries (citizens), actors (stakeholders in the energy value chain) and the main reason why to promote these processes: to combat climate change and ensure a healthier future for all.

\section{Acknowledgements}

This project has received funding from the European Union's Horizon 2020 Research and Innovation Programme under grant agreement No 824441. All related information to the project is available at www.muse-grids.eu.

\section{References}

[1] United Nations, $21^{\text {st }}$ November 2016, New Urban Agenda - Quito Declaration on Sustainable Cities and Human Settlements for All, viewed on 03 November 2020

https://uploads.habitat3.org/hb3/N1639668-English.pdf

[2] United Nations, September 2000, General Assembly resolution 55/2, United Nations Millenium Declaration, viewed on 03 November 2020

https://www.ohchr.org/EN/Professionallnterest/Pages/Millennium.aspx

[3] United Nations, 25 $5^{\text {th }}$ September 2015, Resolution adopted by the General Assembly on 25 September 2015, Transforming our world: the 2030 Agenda for Sustainable Development, viewed on 03 November 2020 https://www.un.org/ga/search/view doc.asp?symbol=A/RES/70/1\&Lang=E

[4] United Nations, $12^{\text {th }}$ December 2015, Paris Agreement, viewed on 03 November 2020 https://treaties.un.org/doc/Publication/CN/2016/CN.735.2016-Eng.pdf

[5] EU Ministers Responsible for Urban Matters on 30 May 2016 in Amsterdam, Urban Agenda for the EU "Pact of Amsterdam", viewed on 03 November 2020

https://ec.europa.eu/regional_policy/sources/policy/themes/urban-development/agenda/pact-ofamsterdam.pdf 
[6] EnergyPLAN, Advanced energy systems analysis computer model, viewed on 04 November 2020, https://www.energyplan.eu/

[7] Directive (EU) 2018/844 of the European Parliament and of the Council of 30 May 2018 amending Directive 2010/31/EU on the energy performance of buildings and Directive 2012/27/EU on energy efficiency (Text with EEA relevance), viewed on 03 November 2020, https://eur-lex.europa.eu/legalcontent/EN/TXT/?uri=CELEX\%3A32018L0844

[8] Directive (EU) 2018/2001 of the European Parliament and of the Council of 11 December 2018 on the promotion of the use of energy from renewable sources (Text with EEA relevance.), viewed on 03 November 2020, https://eur-lex.europa.eu/legal-content/EN/TXT/?uri=CELEX\%3A32018L2001

[9] Directive 2012/27/EU of the European Parliament and of the Council of 25 October 2012 on energy efficiency, amending Directives 2009/125/EC and 2010/30/EU and repealing Directives 2004/8/EC and 2006/32/EC Text with EEA relevance.), viewed on 03 November 2020, https://eur-lex.europa.eu/legalcontent/EN/TXT/?uri=celex\%3A32012L0027

[10] European Commission, 2019, Clean Energy for All Europeans package, viewed on 03 November 2020, https://ec.europa.eu/energy/topics/energy-strategy/clean-energy-all-europeans en

[11] European Commission, Brussels $11^{\text {th }}$ December 2019, Communication from the Commission to the European Parliament, the European Council, the Council, the European Economic and Social Committee and the Committee of the Regions (COM(2019) 640 final), The European Green Deal, viewed on 03 November 2020 https://ec.europa.eu/info/sites/info/files/european-green-deal-communication en.pdf

[12] European Commission, Brussels $14^{\text {th }}$ October 2020, Communication from the Commission to the European Parliament, the Council, the European Economic and Social Committee and the Committee of the Regions (COM(2020) 662 final), viewed on 03 November 2020,

https://ec.europa.eu/energy/sites/ener/files/eu renovation wave strategy.pdf

[13] European Committee of the Regions, viewed on 03 November 2020 https://cor.europa.eu/en

[14] Energy European Commission (2016), EU Building Stock Observatory - Energy European Commission, viewed on 04 November 2020, https://ec.europa.eu/energy/topics/energy-efficiency/energy-efficientbuildings/eu-bso en

[15] Joint EPISCOPE and TABULA Website (2016), Institut Wohnen und Umwelt GmbH, viewed on 04 November 2020, https://episcope.eu/welcome/

[16] Directive 2007/2/EC of the European Parliament and of the Council of 14 March 2007 establishing an Infrastructure for Spatial Information in the European Community (INSPIRE), viewed on 03 November 2020, https://eur-lex.europa.eu/legal-content/EN/ALL/?uri=CELEX\%3A32007L0002

[17] OpenStreetMap , UCL, Bytemark Hosting, viewed on 04 November 2020, https://www.openstreetmap.org/

[18] EPB standards [ISO 52000 family, viewed on 03 November 2020, https://epb.center/support/overview-epb-standards/m1/ [5]

[19] Europa-Universität Flensburg and Halmstad University (2018), Pan-European Thermal Atlas 4.3, DanDomain A/S, viewed on 03 November 2020 https://heatroadmap.eu/peta4/

[20] Hotmaps Project, Hotmaps Project - The open source mapping and planning tool for heating and cooling, IP TELECOM, viewed on 03 November 2020, https://www.hotmaps-project.eu/

[21] Thermos project, Thermos Tool, viewed on 04 November 2020, https://www.thermosproject.eu/thermos-tool/thermos-tool/ 
[22] City Energy Analyst (CEA), City Energy Analyst, viewed on04 November 2020, https://cityenergyanalyst.com/

[23] Planheat, Planheat Tool, viewed on 04 November 2020, http://planheat.eu/the-planheat-tool

[24] Hochschule für Technik Stuttgart, Simstadt tool, viewed on 03 November https://simstadt.hftstuttgart.de/en/3d model.html

[25] OGC standard CityGML Version 2.0, viewed on 03 November 2020, http://www.citygml.org/

[26] doppelintegral GmbH, INSEL, viewed on 04 November 2020, https://www.insel.eu/en/

[27] Solar radiation Data, MERRA-2 meteorological re-analysis, viewed on 04 November 2020, http://www.soda-pro.com/web-services/meteo-data/merra

[28] Eurostat, Energy statistics - cooling and heating degree days (nrg_chdd), viewed on 04 November 2020, https://ec.europa.eu/eurostat/cache/metadata/en/nrg chdd esms.htm 